\title{
PERCEPÇÃO AMBIENTAL DE ALUNOS DO ENSINO FUNDAMENTAL NO MUNICÍPIO DE NOVA PALMA, RS.
}

\author{
Juliana Garlet ${ }^{1}$, Thais Scotti do Canto-Dorow ${ }^{2}$ \\ 1 Engenheira Florestal, Especialista Ambiental, Doutoranda do Programa de Pós-Graduação em Engenharia \\ Florestal, Universidade Federal de Santa Maria, Av. Roraima, 1000, CEP 97105-970, Santa Maria (RS). \\ julianagarlet@yahoo.com.br \\ 2Bióloga, Dra., Professora Adjunta do Departamento de Biologia, Universidade Federal de Santa Maria, Av. Roraima, \\ 1000, CEP 97105-970, Santa Maria (RS). thaisdorow@gmail.com
}

\begin{abstract}
RESUMO
O estudo da percepção ambiental torna-se importante, para que seja possível a compreensão das interrelações entre o homem e o ambiente que o cerca. Assim, o objetivo deste estudo é avaliar a percepção ambiental de alunos do Ensino Fundamental da Escola Municipal Cândida Zasso, de Nova Palma - RS. Para a análise, utilizou-se um questionário constituído por 13 questões sobre ambiente e educação, sendo 12 de múltipla escolha e uma discursiva. Através dos resultados, constatou-se que, de maneira geral, as séries avaliadas apresentaram boa percepção ambiental na maioria das questões, com pequenas diferenças de percepção entre as séries. Os estudantes compreendem a necessidade de preservarem o ambiente onde vivem; porém, necessitam de meios mais eficientes que os façam compreender a importância da mudança de hábitos e atitudes, para uma melhor qualidade de vida. Assim, os resultados deste estudo demonstram a relevância de se trabalhar a Educação Ambiental a partir da realidade escolar, iniciando pelos conceitos mais básicos de preservação, para que os jovens percebam a importância de pequenas atitudes na preservação ambiental.
\end{abstract}

Palavras-chave: Educação Ambiental, Ensino Básico, Meio Ambiente.

\begin{abstract}
The study of environmental perception becomes important to be able to understand the interrelationships between humans and the environment that surrounds it. The aim of this study is to evaluate the environmental perception of Candida Zasso elementary school students in Palma Nova - RS. For the analysis, was used a questionnaire comprising 13 questions about environment and education, with 12 multiple choice questions and one discursive. Through the results, it was found that overall the series evaluated showed good sense in most environmental issues, with small differences in perception between the series. Students understand the need to preserve the environment, but require more efficient means to make them understand the importance of changing habits and attitudes for a better quality of life. Thus, the results of this study demonstrate the importance to work with environmental education from the school, starting with the most basic concepts of preservation, so that young people understand the importance of small actions on environmental preservation.
\end{abstract}


Key words: Environmental Education, Elementary Education, Environment.

\section{INTRODUÇÃO}

Os problemas relacionados ao meio ambiente estão cada vez mais visíveis na sociedade, seja por meio da mídia ou pela percepção de alterações, como na paisagem e no clima. Nesse contexto, a Educação Ambiental torna-se uma importante ferramenta para expandir as discussões e possibilitar a conscientização sobre a importância da conservação dos recursos naturais.

A Educação Ambiental promove os meios de percepção e compreensão dos vários fatores que interagem no tempo e no espaço para modelar o meio ambiente. Também, deve definir os valores e motivações que conduzam a padrões de comportamento de preservação e melhoria desse meio (DIAS, 2003).

Assim, ela representa um dos caminhos viáveis para a conscientização, pois pretende sensibilizar a sociedade, quanto à problemática existente, buscando modificar a percepção ambiental. Como processo educativo, deve ser inserida em todos os componentes curriculares dos níveis de Ensino Básico, como pretende a Política Nacional de Educação Ambiental, através da Lei 9.795/99. Entretanto, para o sucesso dos programas de Educação Ambiental, é importante a adoção de ferramentas adequadas, a fim de que cada grupo atinja o nível esperado de percepção (JACOBI et al., 2004).

A percepção ambiental é definida por Faggionato (2005) como "uma tomada de consciência do ambiente pelo homem"; portanto, através de sua autodefinição, percebe o ambiente em que está localizado, aprendendo a protegê-lo e a cuidá-lo. O estudo dessa percepção é de fundamental importância, para que seja possível a compreensão das interrelações entre o homem, o ambiente e suas expectativas, satisfações e insatisfações, julgamentos e condutas.

O conhecimento da percepção ambiental de determinados grupos possibilita a elaboração de ações de conscientização voltadas a cada realidade regional ou local. No caso de avaliações em escolas, é possível a correta elaboração de conteúdos sobre as questões ambientais, adequados às diferentes séries, realidades e problemáticas.

Assim, o objetivo deste estudo é avaliar a percepção ambiental de alunos do Ensino Fundamental da Escola Municipal Cândida Zasso, de Nova Palma - RS.

\section{MATERIAL E MÉTODOS}

O presente trabalho foi desenvolvido no município de Nova Palma, situado na Mesorregião Centro-Ocidental do Rio Grande do Sul, entre as coordenadas 2928'18"S e 5328'08"W, com altitude de $117 \mathrm{~m}$ e população estimada em 6.693 habitantes (Instituto Brasileiro de Geografia e Estatistica, 2009). Este estudo foi realizado na Escola Municipal Cândida Zasso, localizada no perímetro urbano do município, com alunos do Ensino Fundamental, de 5 a a ${ }^{\text {a }}$ séries, provenientes das zonas urbana e rural.

Foram entrevistados 167 estudantes, sendo 54 da 5a série, 45 da 6a, 35 da 7ạ e 33 da 8ª. Para a análise da percepção ambiental dos estudantes, utilizou-se questionário, constituído por 13 questões sobre ambiente e educação, sendo 12 questões de múltipla escolha e uma discursiva (Figura 1). A pergunta de livre resposta foi analisada conforme a técnica sugerida por 
Pereira (2006) apud Vasconcelos (2005), adaptada ao objetivo deste estudo. Nesse sentido, foram criadas três categorias de indicadores de avaliação: "Satisfatórias", para os alunos que demonstraram ter conhecimento significativo do assunto abordado; "Parcialmente satisfatórias", para os que demonstraram ter conhecimento mínimo do assunto abordado; "Insatisfatórias", para os que demonstraram ou declararam não saber nada sobre o assunto ou, ainda, quando não responderam à questão.

Através das porcentagens das respostas em cada categoria, foram observadas as diferenças entre os alunos das séries avaliadas ( $5^{\underline{a}}$ a $8^{\underline{a}}$ séries). Quanto às perguntas de múltipla escolha, as respostas foram agrupadas, a fim de avaliar qual obteve a maior porcentagem de escolha. 
GARLET et al, vol.(4), n4, p. 773-785, 2011.

Monografias Ambientais

(e-ISSN: 2236-1308)

REMOA

Questionário de avaliação da percepção ambiental de alunos do ensino fundamental da escola municipal Cândida Zasso em Nova Falma-RS

Nome:

Série:

Residena:

( ) Zona Urbana

1 - Você jé ouviu falar em Educação ambiental?
( ) Não

2 - Quais disciplin

( ) Zona Rural

( ) Geografia

( ) Ciências

( ) Outra disciplina, qual

( ) Todas

( ) Nenhuma

3. Você considera importante uma disciplina de Educação ambiental em sua escola?
() Sim
() Não

4 - Você considera que existem problemas ambientais em seu município?
( ) Sim
( ) Não

5 - Quais os principais problemas ambientais observados? (Pode marcar mais de uma opção)

( ) Lixo

( ) Queimadas

( ) Desmatamento

( ) Poluição do ar

( ) Poluição das águas

( ) Caça de animais silvestres

( ) Outros. Quais

( ) Não existem problemas ambientais

6 - E. em sua escola. você considera que há problemas ambientais?
() Sim
() Não

7 - Quais os principais problemas ambientais observados em sua escola? (Pode marcar mais de uma opção)

( ) Lixo

( ) Poluiçãovisual (paredes riscadas)

( ) Outros. Quais.

( ) Não existem problemas ambientais

8 - Você considera que os rios de sua cidade são poluidos?
( ) $\mathrm{Sim}$
( ) Não

9 - Qual o principal problema ambiental dos rios de sua cidade?

( ) Lixo

( ) Esgoto

( ) Não há problemas

10 - Você considera importante a preservação da natureza?
( ) $\mathrm{Sim}$
( ) Não

11 - Em sua opiniăo a responsabilidade pelos problemas ambientais é?

( ) Governo

( ) Escola

( ) Todos

( ) Ninguém

12 - Você contribui para a preservação do meio ambiente?
( ) $\operatorname{Sim}$
( ) Não

13 - Se você considera que contribui para a preservação do meio ambiente, escreva algumas atitudes que você tem que contribuem para a melhoria do ambiente onde você vive.

Figura 1: Questionário utilizado para avaliar a percepção ambiental dos alunos de Ensino Fundamental de Nova Palma, RS. 
REMOA

\section{RESULTADOS E DISCUSSÃO}

Os resultados obtidos neste estudo são apresentados nas figuras e tabelas a seguir. Na questão 1, perguntou-se aos estudantes se já conheciam o termo Educação Ambiental, os quais deveriam responder "Sim" ou "Não", conforme resultados da Figura 2.

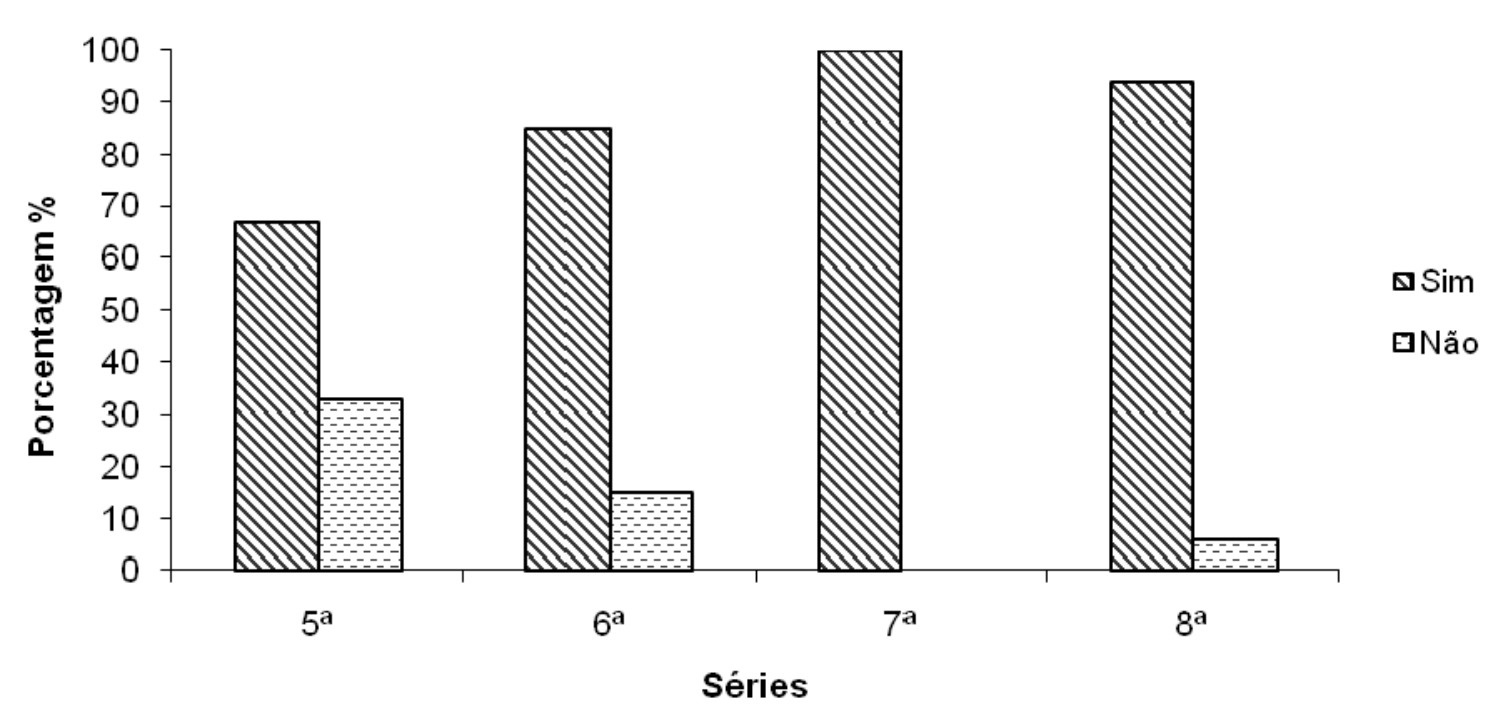

Figura 2: Respostas dos alunos da Escola Cândida Zasso, Nova Palma, RS, sobre conhecimento do termo Educação Ambiental.

A maioria dos alunos reconhece o termo Educação Ambiental, sendo possível constatar que o aumento da escolaridade é diretamente proporcional ao conhecimento acerca do assunto. O decréscimo observado da 7ạ para a 8 $^{a}$ série pode estar relacionado à falta de comprometimento de alguns entrevistados em relação ao questionário aplicado. Em estudo de Costa e Araújo (2009), no Maranhão, com alunos do Ensino Fundamental, de 1ạ a 8a séries, foi observado que $90 \%$ deles demostraram conhecer o termo Educação Ambiental. Neste estudo, ao realizar a média das quatro séries avaliadas, chega-se ao percentual de $84 \%$, inferior ao encontrado pelos autores no Maranhão. Uma explicação para a diferença de percentual pode ser o trabalho mais efetivo da escola em ações ambientais.

Na questão 2, os alunos responderam à seguinte pergunta: Quais disciplinas abordam a questão ambiental em sua escola? (Figura 3). 


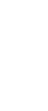

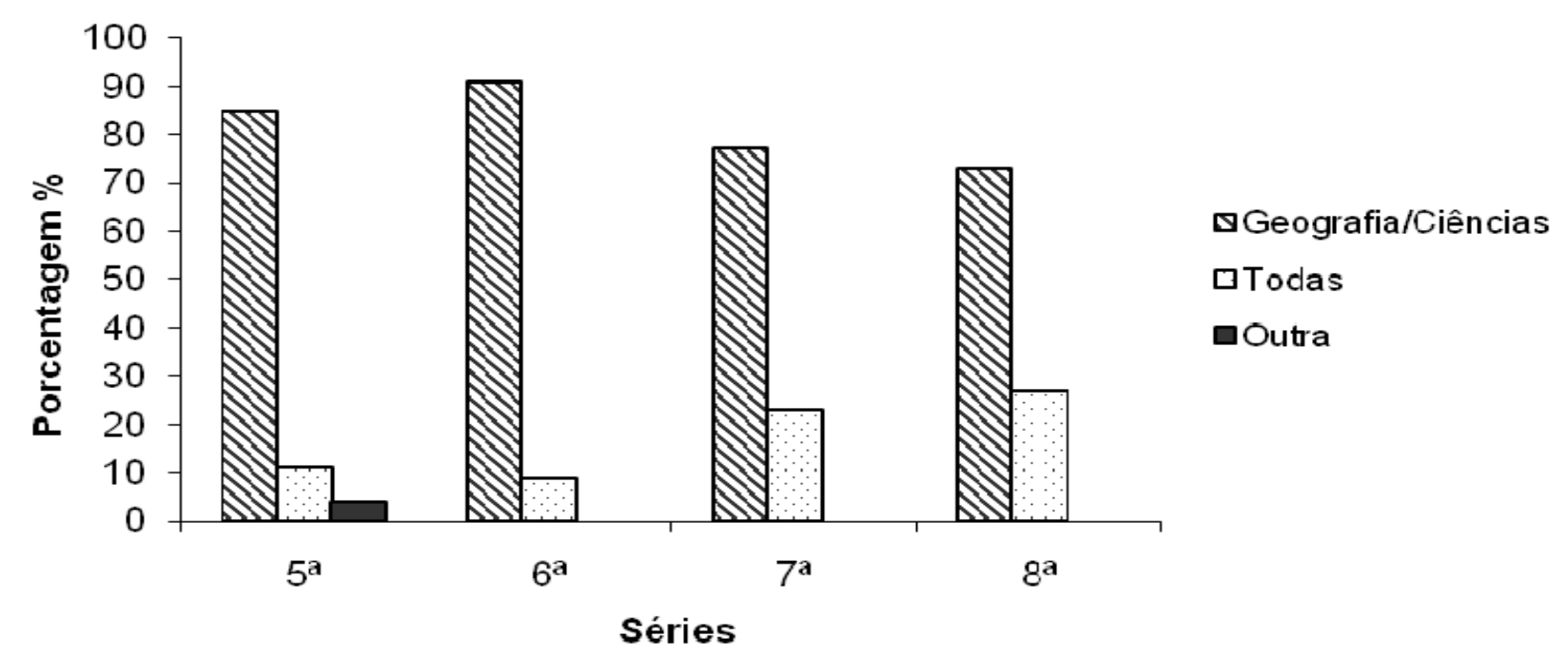

Figura 3: Porcentagem das respostas dos alunos em relação a quais disciplinas abordam a questão ambiental na Escola Cândida Zasso, Nova Palma, RS.

Verifica-se que grande parte dos estudantes acredita que as disciplinas de Geografia e Ciências são as que mais tratam das questões ambientais na escola. A alta porcentagem de alunos que citaram tais disciplinas pode estar relacionada ao conteúdo abordado nesses componentes, o que torna mais fácil a abordagem dos temas ambientais em sala de aula.

$\mathrm{Na} 7 \underline{\text { a e }} 8^{\mathrm{a}}$ séries, constata-se o aumento do número de alunos que considera que todas as disciplinas abordam a questão ambiental. Nesse sentido, destaca-se que a idade também influencia na percepção de que outros componentes curriculares abordam o assunto. Segundo Melazo (2005), a idade, escolaridade, e experiências, em se tratando de aspectos socioambientais, influenciam na percepção ambiental dos indivíduos; assim, alunos da 8a série, pela idade mais elevada, possuem capacidade superior de relacionar a Educação Ambiental às diversas disciplinas e a diversos temas.

Barcelos (2009) destaca que a ligação direta do conceito de Educação Ambiental às disciplinas de Geografia e Ciências tem analogia com as discussões históricas dos professores com as questões ambientais. No entanto, o autor considera uma "mentira" que Educação Ambiental na escola seja discutida somente pelos educadores de disciplinas ligadas a recursos naturais. Esse tema deve estar presente nos diversos conteúdos curriculares tratados em sala de aula, para que se possa alcançar o objetivo desejado.

$\mathrm{Na}$ questão 3, pergunta-se sobre a importância da inclusão de uma disciplina de Educação Ambiental na escola (Figura 4). 


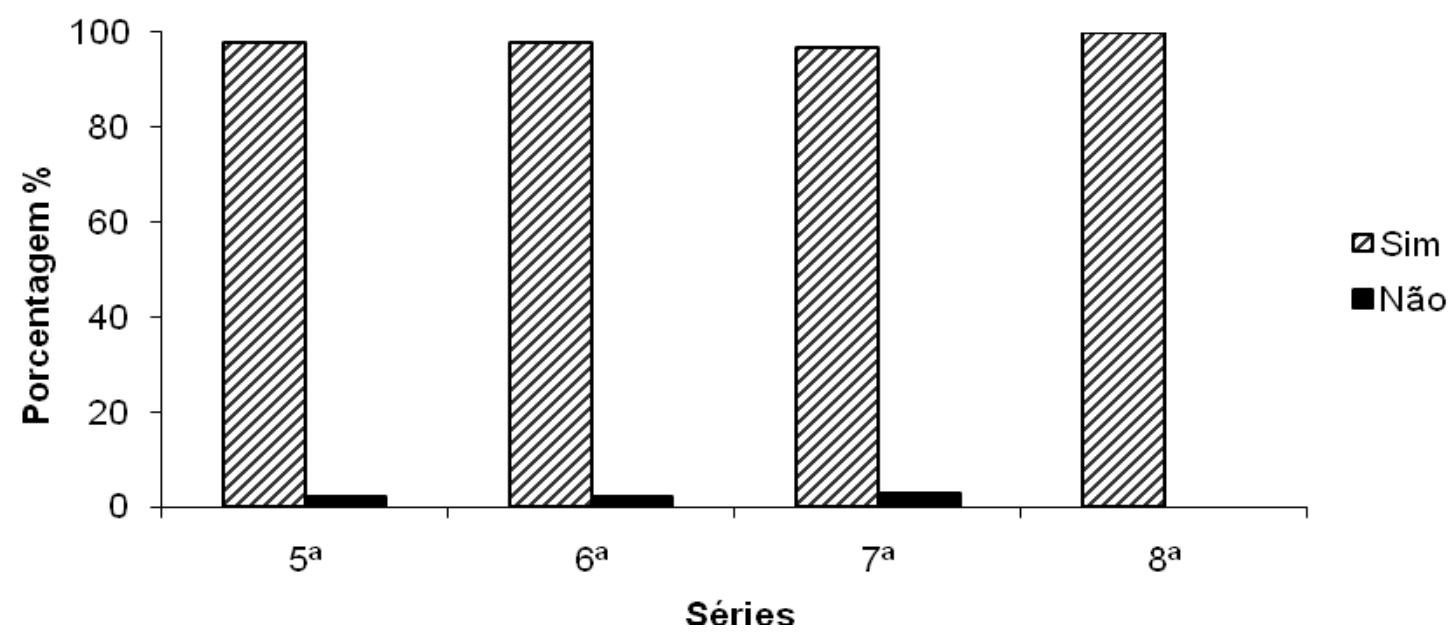

Figura 4: Porcentagem das respostas dos alunos que consideram importante ou não a existência de uma disciplina de Educação Ambiental na Escola Cândida Zasso, Nova Palma, RS.

Em todas as séries avaliadas, cerca de $97 \%$ dos entrevistados consideram importante a existência de uma disciplina específica de Educação Ambiental. Tal índice pode ter relação com o trabalho que a escola realiza, envolvendo os alunos em algumas atividades de Educação Ambiental, como plantio de árvores em áreas de preservação permanente, o que os estimula a sentirem necessidade da disciplina.

Gonçalves (1999) defende como procedimento para Educação Ambiental uma "metodologia de ação", de forma a tirar o estudante da posição de mero espectador que o cerca para colocálo como um real participante dessa realidade, permitindo-lhe desenvolver o pensamento consciente, reflexivo e crítico.

As questões 4 e 5 aludem aos problemas ambientais observados em Nova Palma. Na questão 4, os alunos responderam se consideram a existência de problemas ambientais no município; na questão 5, citaram quais são os problemas: lixo, queimadas, caça de animais silvestres, desmatamento, poluição do ar e das águas. Na avaliação, utilizou-se o "Sim" para os alunos que optaram por uma ou mais alternativas e o "Não" para os que responderam que não existem problemas ambientais no município (Tabela 1 ). 
GARLET et al, vol.(4), n4, p. 773-785, 2011. Monografias Ambientais (e-ISSN: 2236-1308)

REMOA

Tabela 1: Porcentagem das respostas dos alunos em relação à existência e aos tipos de problemas ambientais no município de Nova Palma, RS.

$$
\text { Questão } 4 \text { Questão } 5
$$

\begin{tabular}{ccccc} 
Séries & Sim \% & Não \% & Sim \% & Não \% \\
\cline { 2 - 5 } & 92 & 8 & 98 & 2 \\
\hline $5^{\mathrm{a}}$ & 87 & 13 & 98 & 2 \\
\hline $6^{\mathrm{a}}$ & 94 & 6 & 100 & 0 \\
\hline $7^{\mathrm{a}}$ & 100 & 0 & 100 & 0 \\
\hline $8^{\mathrm{a}}$ & & &
\end{tabular}

Na questão 4, constata-se, na 6a série, a menor porcentagem de alunos que acredita na existência de problemas ambientais no município; na 8a série, a maior porcentagem (100\%) observa os problemas. Quanto à questão 5 , a porcentagem de alunos que acredita haver problemas ambientais aumenta, pois receberam exemplos (queimadas, desmatamento, poluição, etc.) como subsídios, ao contrário do que ocorreu com a questão 4. Leff (2005), ao discutir sobre a problemática ambiental identificada em situações de ensino-aprendizagem, faz a dissociação do contexto socioeconômico e cultural, isto é, da realidade na qual estão inseridos professores e alunos. Isto dificultaria a percepção e compreensão dos mesmos em razão da complexidade do meio em que vivem, sendo, portanto, uma possível explicação das razões pelas quais não identificaram os problemas ambientais diretamente na primeira questão.

Nesse sentido, Miranda (2008) destaca que os jovens constituem o público-alvo mais promissor no processo de Educação Ambiental, pois sua consciência ambiental pode ser internalizada de maneira mais bem sucedida do que em adultos já formados e com comportamentos enraizados. Além de representarem as gerações futuras, eles também são multiplicadores eficazes na ação de estimular a análise crítica das questões ambientais e sociais na comunidade.

As questões 6 e 7 estão referenciam o ambiente escolar: na 6, pergunta-se sobre a presença/ausência de problemas ambientais na escola; na 7, questiona-se quais são os principais problemas, sendo fornecidas alternativas, como lixo, poluição visual. Na avaliação, utilizou-se o "Sim" para os alunos que optaram por uma ou mais alternativas e o "Não" para os que responderam que não existem problemas (Tabela 2). 
GARLET et al, vol.(4), n4, p. 773-785, 2011. Monografias Ambientais

(e-ISSN: 2236-1308)

REMOA

Tabela 2: Porcentagem das respostas dos alunos em relação à existência e aos tipos de problemas ambientais na Escola Cândida Zasso, Nova Palma, RS.

Questão 6

Questão 7

Séries

\begin{tabular}{lllll}
\hline $5^{\mathrm{a}}$ & 66 & 39 & 89 & 11 \\
\hline $6^{\mathrm{a}}$ & 56 & 44 & 85 & 15 \\
\hline $7^{\mathrm{a}}$ & 57 & 43 & 83 & 17 \\
\hline $8^{\mathrm{a}}$ & 49 & 51 & 57 & 43 \\
\hline
\end{tabular}

Pode-se verificar a semelhança entre as questões 4 e 6 . Constata-se que um número expressivo de alunos considera não haver problemas ambientais na escola, sendo a maioria da $8^{a}$ série. No entanto, quando apresentadas as alternativas (questões 5 e 7), houve acréscimo de alunos que responderam "Sim", demostrando que, para alguns, os problemas observados, num primeiro momento, não são ambientais.

As questões 8 e 9 abordam a situação dos rios de Nova Palma. Na questão 8, foi questionado se os rios da cidade são poluídos; na questão 9, qual a principal causa, sendo fornecidas alternativas, como lixo e esgoto. A resposta "Sim" é para os estudantes que responderam uma ou ambas alternativas; a "Não", para os que responderam não haver problemas ambientais (Tabela 3).

Tabela 3: Porcentagem das respostas dos alunos da Escola Cândida Zasso, Nova Palma, RS, em relação à situação dos rios no município de Nova Palma, RS.

\begin{tabular}{ccccc}
\hline \multirow{2}{*}{ Séries } & \multicolumn{2}{c}{ Questão 8 } & \multicolumn{2}{c}{ Questão 9 } \\
\cline { 2 - 5 } & Sim \% & Não \% & Sim \% & Não \% \\
\hline $5^{\mathrm{a}}$ & 96 & 4 & 100 & 0 \\
\hline $6^{\mathrm{a}}$ & 96 & 4 & 100 & 0 \\
\hline $7^{\mathrm{a}}$ & 97 & 3 & 100 & 0 \\
\hline $8^{\mathrm{a}}$ & 100 & 0 & 100 & 0 \\
\hline
\end{tabular}

Através dessas informações, observa-se, novamente, que, num primeiro momento, alguns estudantes não percebem problemas nos rios do município, no entanto, quando fornecidas as alternativas (questão 9), as situações foram identificadas. Assim, a totalidade dos entrevistados alegou existirem problemas ambientais nos rios.

As questões 10, 11 e 12 abordaram, respectivamente, temas relacionados à importância da preservação da natureza, responsabilidade pelos problemas ambientais e contribuição para a preservação do meio ambiente (Tabela 4). 
Tabela 4: Porcentagem das respostas dos alunos da Escola Cândida Zasso, Nova Palma, RS, em relação à importância, contribuição e responsabilidade pela preservação da natureza.

Questão 10 Questão $11 \quad$ Questão 12

\begin{tabular}{cccccccc}
\hline $5 \underline{a}$ & 100 & 0 & 5 & 0 & 95 & 100 & 0 \\
\hline $6 \underline{a}$ & 98 & 2 & 4 & 2 & 94 & 98 & 2 \\
\hline $7 \underline{a}$ & 100 & 0 & 0 & 0 & 100 & 100 & 0 \\
\hline $8^{a}$ & 100 & 0 & 3 & 0 & 97 & 100 & 0 \\
\hline Séries & Sim \% & Não $\%$ & Governo \% & Escola\% Todos & Sim \% & Não \%
\end{tabular}

$\mathrm{Na}$ questão 10, quase a totalidade dos alunos concordou que é importante a preservação da natureza e aponta que a responsabilidade é de todos; alguns destacaram que a responsabilidade é também do governo; outros, da escola (resposta encontrada somente na 6a série). Na questão 12 , praticamente $100 \%$ responderam que contribuem de alguma forma para a preservação do meio ambiente.

$\mathrm{Na}$ questão 13, única de livre resposta, indagou-se aos alunos se contribuíam para a preservação do meio ambiente e quais atitudes são adotadas para tal (Tabela 5).

Tabela 5: Percentual das respostas dos alunos da Escola Cândida Zasso, Nova Palma, RS, em relação à contribuição e atitudes para a preservação do meio ambiente.

\begin{tabular}{cccc}
\hline Séries & Satisfatórias \% & Parcialmente satisfatórias \% & Insatisfatórias \% \\
\hline 5 a & 40 & 59 & 0 \\
\hline 6 a & 30 & 62 & 8 \\
\hline $7 a$ & 38 & 48 & 14 \\
\hline 8 a & 46 & 36 & 18 \\
\hline
\end{tabular}

Observando-se os dados, constatou-se que os alunos da 5 ạ série responderam de forma satisfatória a pergunta, sem se enquadrarem na categoria "Insatisfatórias". Nota-se, também, aumento da porcentagem no quesito "Insatisfatórias" pelos alunos de 5a para a 8a série, em virtude de não haver resposta ou por não terem qualquer atitude para a melhoria do meio onde vivem.

Quanto às ações, a resposta mais apresentada foi a de não jogar lixo no chão, em $98 \%$ dos casos. Entre os alunos da 5a e 6a séries, as respostas foram conscientes, como "converso com o meu pai para que ele não passe mais agrotóxicos próximo aos córregos"; "falo para a minha mãe economizar água, usando da máquina para lavar a calçada e molhar as plantas" e "não deixo meus amigos matarem passarinhos". As respostas de maior representatividade estão relacionadas às temáticas lixo, consumo de água, descarte de embalagens de agrotóxicos, pois são recorrentes em campanhas desenvolvidas pela mídia, tornando-se habitual no cotidiano dos estudantes. 
Outra observação é referente aos alunos da 7ạ e $8^{\underline{a}}$ séries: alguns responderam positivamente; outros, não identificam pequenas atitudes como importantes para a conservação do ambiente onde vivem, não citando nem o simples fato de "colocar o lixo no lugar adequado" como uma ação necessária. Gonçalves et al. (2009), avaliando a percepção ambiental de alunos do Ensino Fundamental, em Belo Horizonte, observaram que a percepção de estudantes das séries inferiores foi mais significativa em comparação com os da 8 a série. Este trabalho apresenta resultados semelhantes, sendo uma possível explicação o fato de que somente temas ambientais são discutidos com maior intensidade, proporcionando aos alunos das séries iniciais maior conhecimento e conscientização das questões ambientais.

$\mathrm{Na}$ questão 13, os alunos da $5^{\mathfrak{a}}$ série apresentaram percepção ambiental mais significativa quando comparados aos da $8^{a}$ série, por não haver respostas não satisfatórias e por não conseguirem identificar as pequenas atitudes como importantes para a preservação do ambiente onde vivem.

Este trabalho apresenta resultados semelhantes aos encontrados por Oliveira (2006), o qual aborda que os participantes do estudo, de uma maneira geral, sabem do que precisam fazer para melhorar o ambiente onde vivem; porém, necessitam de meios mais eficientes que os façam compreender a importância de mudanças de hábitos e atitudes, para uma melhor qualidade de vida. Marczwski (2006), em estudo desenvolvido em Caxias do Sul-RS, observou que aos alunos da $5 \underline{a}$ série apresentaram respostas sobre as questões ambientais aquém do esperado; nas demais séries do Ensino Fundamental, as respostas estavam de acordo com o esperado.

Segundo Brandão (2001), através da criticidade, criatividade e afetividade dos educandos, faz-se com que a educação cumpra seu papel, que é o de fomentar o desenvolvimento do ser humano de maneira integral. Guimarães (1995) destaca que o meio ambiente é uma sinonímia da palavra natureza. O que chamamos de natureza ou meio ambiente trata-se de um conjunto de elementos vivos e não vivos que constituem o planeta, os quais se relacionam, influenciando e sofrendo influência entre si, em um equilíbrio dinâmico. O mesmo autor ressalta, ainda, que o aluno deve ser parte integrante do processo de educação, como um disseminador das questões ambientais pertinentes em sua escola, município, cidade, país, percebendo os resultados de suas práticas no ambiente que o cerca.

Para Gonçalves (1999), a Educação Ambiental é um processo longo e contínuo de uma filosofia de trabalho principalmente participativa, em que todos, família, escola e comunidade, devem estar envolvidos, tendo a preocupação de transmitir conhecimentos a partir da discussão e avaliação feitas pelo aluno da sua realidade individual e social na comunidade em que vive.

Miranda (2008) destaca ainda que, atualmente, é essencial que se repense a Educação Ambiental nas escolas tal como ela é concebida nos dias atuais, direcionada apenas para a transmissão de teorias e conhecimentos sobre ecologia. É necessário que ela tenha como objetivo não só os ensinamentos aos alunos sobre a utilização racional dos recursos que a natureza oferece, mas que consiga ultrapassar os muros das escolas, buscando participação permanente da comunidade nas discussões e nas decisões sobre as questões ambientais.

O autor também destaca que a Educação Ambiental pode ser um estimulante espaço para repensar práticas sociais e que o papel dos professores é o de ser mediadores e transmissores de um conhecimento necessário para que os alunos adquiram base adequada de compreensão do meio ambiente global e local. 
REMOA

\section{CONCLUSÃO}

De forma geral, as séries avaliadas possuem boa percepção ambiental, apenas na questão 1 , os estudantes mostraram percentuais mais elevados sobre o desconhecimento do termo Educação Ambiental; nas demais, os valores foram próximos. Deste modo, conclui-se que, a percepção ambiental pode variar de região para região, de acordo com a realidade dos estudantes, assim como entre as séries avaliadas.

\section{CONSIDERAÇÕES FINAIS}

Os resultados deste estudo demonstram a relevância de se trabalhar a Educação Ambiental a partir da realidade escolar, iniciando pelos conceitos mais básicos de preservação, para que os estudantes percebam a importância de pequenas atitudes, como o destino adequado do lixo. A falta de comprometimento observada em alguns questionários, principalmente da 8 a série, revelam que apesar dos estudantes, conhecerem as noções básicas de meio-ambiente, estes não dão a devida importância ao assunto, sendo um foco importante de trabalho para a educação ambiental.

Assim, este estudo poderá ser utilizado como uma ferramenta de auxílio aos docentes da escola na preparação de trabalhos ligados à temática ambiental, como palestras e oficinas, de acordo com algumas problemáticas abordadas nas diferentes séries avaliadas, realizando atividades focadas para cada grupo analisado. Considera-se importante também a criação de uma disciplina de Educação Ambiental na escola, pois os próprios alunos demonstraram interesse em sua existência.

\section{REFERÊNCIAS BIBLIOGRÁFICAS}

BARCELOS, V. Educação Ambiental: sobre princípios, metodologias e atitudes. Petrópolis: Vozes, 2009. 119 p.

BRANDÃO, C. R. O que é educação. 39.ed. São Paulo: Brasiliense, 2001.

BRASIL. Conselho Nacional do Meio Ambiente. Lei 9.795, de 27 de abril de 1999, Dispõe sobre a educação ambiental, institui a Política Nacional de Educação Ambiental e dá outras providências.

Diário Oficial da

$$
\text { União, } 28 \quad \text { abr. } 1999 . \quad \text { Disponível }
$$

em:<http://www.mma.gov.br/port/conama/legiabre.cfm?codlegi=321>. Acesso em: 27 mai. 2010.

COSTA, A. C.; ARAUJO, A. Percepção ambiental dos alunos de uma escola da rede pública municipal da cidade de Raposa - MA. $2009 . \quad$ Disponível em:

<http://recantodasletras.uol.com.br/trabalhosacademicos/1759863>. Acesso em: 9 jun. 2010.

DIAS, G.F. Educação ambiental: princípios e práticas. 8.ed. São Paulo: Gaia, 2003. FAGGIONATO, Sandra. 2005. Disponível em: <http://educar.sc.usp.br>. Acesso em: 10 mai. 2010.

FERRARI, R. et al. Conflitos no uso e cobertura da terra no município de Nova Palma, RS. Ciência e Natura, UFSM, 30 (2): p.127- 139, 2008.

GONÇALVES, A. A.; LIMA, M.E. O.; MARQUES, M.R. A percepção e educação ambiental com alunos do ensino fundamental. $2009 . \quad$ Disponível em 


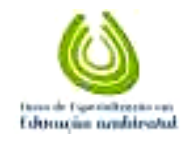

GARLET et al, vol.(4), n4, p. 773-785, 2011. Monografias Ambientais

(e-ISSN: 2236-1308)

REMOA

<legal2009.easyplanners.info/.../3436_Goncalves_Alexandra_Andrade_Goncalves.doc:>. Acesso em: 9 jun. 2010.

GONÇALVES, W. Florestas Urbanas. Ação ambiental. Porto Alegre: Ed. Cinco Continentes, 1999.

GUIMARÃES, M. A dimensão ambiental na educação. Campinas: Papirus, 1995.

IBGE. 2009. Nova Palma. Disponível em: <http://www.ibge.gov.br/cidadesat/topwindow.htm?1>. Acesso em: Acesso em: 22 abr. 2010. JACOBI, C.M.; FLEURY, L.C.; ROCHA, A.C.C.L. Percepção ambiental em unidades de conservação: experiência com diferentes grupos etários no Parque Estadual da Serra do Rola Moça, MG. In: 70 ENCONTRO DE EXTENSÃO DA UNIVERSIDADE FEDERAL DE MINAS GERAIS, 2004, Belo Horizonte. Anais... Universidade Federal de Minas Gerais, 2004.

LEFF, E. Saber ambiental: Sustentabilidade,Racionalidade, Complexidade, Poder. Petrópolis: Vozes, 2005.

MARCZWSKI, M. Avaliação da percepção ambiental em uma população de estudantes do ensino fundamental de uma escola municipal rural: Um estudo de caso. 2006. 188 f. Dissertação (Mestrado em Ecologia). Universidade Federal do Rio Grande do Sul, Porto Alegre, 2006.

MELAZO, G. C. Percepção ambiental e educação ambiental: Uma reflexão sobre as relações interpessoais e ambientais no espaço urbano. Olhares \& Trilhas. Uberlândia, n. 6, p. 45-51, 2005.

MIRANDA, A.M. 2008. In: Percepção ambiental: 0 despertar para o conhecimento científico através de uma horta educativa. 10 Encontro de Educação do Colégio Gonçalves Dias. Disponível em: <www.gd.g12.br/eegd>. Acesso em: 24 mai. 2010.

OLIVEIRA, N. A. S. A percepção dos resíduos sólidos (lixo) de origem domiciliar, no bairro Cajuru - Curitiba-PR: um olhar reflexivo a partir da educação ambiental. 2006. 174 f. Dissertação (Mestrado em Geografia). Curso de Pós-Graduação em Geografia, Universidade Federal do Paraná, Curitiba, 2006.

PEREIRA, E. M.; FARRAPEIRA, C. M. R.; PINTO, S. L. Percepção e educação ambiental sobre manguezais em escolas públicas da Região Metropolitana do Recife. Rev. eletrônica Mestr. Educ. Ambient., v.17, 2006.

SEGURA, D. S. B. Educação ambiental na escola pública: da curiosidade ingênua à consciência crítica. São Paulo: Annablume/FAPESP, 2001. 